\title{
短時間インターバル形式の一過性運動が脈波伝搬速度に及ぼす影響
}

\author{
出口 憲市 ${ }^{1}$, 三浦 哉 ${ }^{2}$
}

\section{Effect of acute short-term high and moderate-intensity interval exercise on pulse wave velocity}

\author{
Kenichi Deguchi ${ }^{1}$ and Hajime Miura ${ }^{2}$ \\ 1 徳島大学病院リハビリテーション部， $7770-8503$ 徳島県徳島市蔵本町 2-50-1 (Department of Rehabilitation, Tokushima \\ University Hospital, 2-50-1 Kuramoto-cho, Tokushima 770-8503, Japan) \\ 2 徳島大学大学院ソシオ・アーツ・アンド・サイエンス研究部, ₹770-8502 徳島県徳島市南常三島 1-1 (Laboratory for \\ Applied Physiology, Institute of Socio-Arts and Science, University of Tokushima, 1-1 Minamijyosanjima, Tokushima 770- \\ 8502, Japan)
}

Received: April 1, 2014 / Accepted: July 3, 2014

\begin{abstract}
Interval training has a beneficial effect for treating the cardiovascular disease. However, it is not clarify the effects of different exercise intensity and duration on arterial function. In the present study, we evaluated the effect of acute short-term high and moderateintensity interval exercise on pulse wave velocity. Thirteen healthy men were randomly assigned to perform both acute interval exercise (IE; cycling for $24.6 \mathrm{~min}$ at $80 \% \mathrm{VO}_{2}$ max and $50 \% \mathrm{VO}_{2} \mathrm{max}$ ) and acute continuous moderate-intensity exercise (CME; cycling for $30 \mathrm{~min}$ at $50 \% \mathrm{VO}_{2} \max$ ). The IE and CME protocols were designed such that the exercises resulted in the same workload during each session. The brachial systolic and diastolic blood pressure (SBP and DBP), and brachial to ankle pulse wave velocity (baPWV) were obtained in the supine position using an automatic pulse wave form analyzer at pre- and post-exercise. In IE, baPWV at postexercise decreased significantly compared with pre-exercise value $\left(1181.9 \pm 119.2 \mathrm{~cm} \cdot \mathrm{sec}^{-1} \mathrm{vs}\right.$. $\left.1108.4 \pm 109.4 \mathrm{~cm} \cdot \mathrm{sec}^{-1}, \mathrm{p}<0.01\right)$. In CME, however, it was not significantly different between pre- and post-exercise values $\left(1173.5 \pm 137.1 \mathrm{~cm} \cdot \mathrm{sec}^{-1}\right.$ vs. $\left.1164.8 \pm 96.0 \mathrm{~cm} \cdot \mathrm{sec}^{-1}, \mathrm{p}=\mathrm{ns}\right)$. No significant differences in SBP and DBP were found both protocols. These results suggest that acute short-term high and moderate-intensity interval exercise was more effective in reducing baPWV compared with acute continuous exercise.
\end{abstract}

Jpn J Phys Fitness Sports Med, 63(5): 475-480 (2014)

Keywords : acute interval exercise, short-term, pulse wave velocity

\section{緒言}

わが国の 2010年の全死因に占める死因別死亡数の割合 は, 循環器疾患の代表である心疾患および脳血管疾患が 約 $26.5 \%$ であり, 悪性新生物の割合 $(30.1 \%)$ と同等である ${ }^{1)}$. また, 循環器疾患の代表である高血圧症の原因として, 動脈スティフネスの増加 ${ }^{2}$ があげられ，その代表的な指 標である脈波伝搬速度 (Pulse Wave Velocity: PWV) は, 加齢により上昇し, 心血管系疾患の独立した危険因子と 報告されている3)。これまでに定期的な有酸素性運動は 中心動脈の伸展性を改善し ${ }^{4)}$, その代表的な持久的卜レー ニングは, 主に一定強度を持続的に実施する持続的卜 レーニングと高強度運動および低〜中強度運動を繰り返 すインターバルトレーニングとに分けられる。インター バルトレーニングでは, 中強度の持続的トレーニングと
比較して血管内皮機能の著しい改善が報告 ${ }^{5,6)}$ されてお り, インターバル形式の一過性運動でも心拍出量の増加 およびnitric oxide (NO) が安静時と比較して, より一層 増加したと報告されている7,8)。しかし, 高強度運動は, 高齢者でも良好な健康状態を維持するために実施するこ とを推奨されている ${ }^{9)}$ が, 心負荷の増加のために致死的 不整脈の発生, 高血圧症患者では血圧上昇などのリスク が高くなると報告されている10)。 そのために, 循環器疾 患の一次予防を目的としたインターバルトレーニングで は, 心負荷のリスクを軽減するために高強度運動の設定 を低くして短時間にする必要があるが，これらの条件で の運動が動脈機能に及ぼす影響については十分に検討さ れていない

Ciolac $^{7)}$ らは, インターバル形式の一過性運動後に運動 前と比較してNOがより一層増加したと報告しており, 
さらに同じプロトコールでのインターバルトレーニング 前後では, PWVが低下したと報告している。したがって, 運動による血流量の増加にともなう shear stress の増加 により，内皮細胞から NOを放出するといった一過性の 変化が生じ，定期的な運動により持続することで機能因 子の改善につながるために，一過性運動が動脈機能に及 ぼす影響を検討することは重要と考えられる。そこで本 研究では, 安全面への配慮から中高齢者ではなく, 高強 度運動が推奨されている若年者を対象者に，短時間の高 強度および中強度運動から構成されるインターバル形式 の一過性運動が高血圧治療ガイドライン ${ }^{11)}$ で推奨されて いる持続的運動と比較して脈波伝搬速度に及ぼす影響を 検討した。

\section{方法}

被験者 被験者は，非喫煙者で運動習慣および末梢動脈 疾患のない成人男性 15 名, 年齢: $25.6 \pm 3.2$ 歳, 身長: 175.0 $\pm 3.9 \mathrm{~cm}$, 体重: $69.7 \pm 9.3 \mathrm{~kg}$, BMI: $22.8 \pm 3.4 \mathrm{~kg} \cdot \mathrm{m}^{-2}$, ABI: $1.1 \pm 0.1$ および $\mathrm{V}_{2 \max }: 34.6 \pm 5.8 \mathrm{ml} \cdot \mathrm{kg}^{-1} \cdot \mathrm{min}^{-1}$ であり，高血圧治療ガイドラインによる I 度高血圧以上 の 2 名を除外し，13名を解析対象者とした。本研究は， 徳島大学総合科学部人間科学分野における研究倫理委員 会の承諾を得たものであり，対象者には事前に文章およ び口頭にて研究内容・趣旨, 参加の拒否・撤回 - 中断な どについて説明し，承諾を得た後に研究を開始した。

最大運動負荷テスト一過性運動時の各運動強度の仕事 量を設定するために, 自転車エルゴメー夕 (232C MODEL50: Combi社製）を使用し, 東大式の多段階負荷法を 一部改訂して最大酸素摂取量 $\left(\dot{\mathrm{V}} \mathrm{O}_{2 \max }\right)$ を測定した $\left.{ }^{12}\right)$. 被験者は, 自転車エルゴメータに座り 3 分間の安静後 に90 Wattsの負荷から開始し， 3 分毎に30 Watts漸増, 9 分後からは 1 分毎に 15 Watts 漸増させる漸増負荷法 による最大負荷テストを実施した。

一過性運動のプロトコール 一過性運動は, 自転車エル ゴメー夕を使用し，高強度と中強度運動から構成され る短時間のインターバル形式の運動（Interval exercise： IE）条件および中強度の持続的運動（Continuous moderate exercise: CME) 条件をそれぞれ 1 回, 無作為の順 序で 3 日以上の間隔をあけて実施した。IE条件の運動 強度は $80 \% \dot{\mathrm{V}} \mathrm{O}_{2 \max }$ 抢よび中強度運動を $50 \% \dot{\mathrm{V}} \mathrm{O}_{2 \max }$ とし て、インターバルトレーニングでの血中乳酸除去が促進 される比率㧍よび運動時間である $1: 1$ および 3 分間ず つを繰り返す設定とした ${ }^{13,14)}$ 。まず，5 分間の中強度運 動の後，3 分毎に高強度運動を 3 回繰り返し，4.6分間 の中強度運動で終了する24.6分間の設定とし，CME条 件は，日本高血圧治療ガイドラインで推奨されている
$50 \% \dot{\mathrm{V}}_{2 \max }$ で30分間の設定とした。なお，両条件間で の各個人の運動時の相対的な仕事量を同一になるように 設定した。

測定項目 $\mathrm{V}_{2}$ の測定は, 自動呼気ガス分析装置 $(\mathrm{AR}-1$ Type-3: アルコシステム製) を用いて，30秒毎に酸素濃 度，炭酸ガス濃度，換気量を分析し，心拍数（HR）の 測定はハートレイトモニター（PUX-1001: NISSEI社製） を用いて記録した。また，一過性運動中の両条件時の $\dot{\mathrm{V}} \mathrm{O}_{2}$ およびHRも同様の方法にて測定した。

一過性運動前後の両上腕㧍よび両足首の収縮期血圧 (SBP)，拡張期血圧 (DBP), 脈圧，上腕から足首間の脈 波伝搬速度（baPWV）およびHRの測定には，血圧脈波 検査装置（form PWV/ABI: オムロンコーリン社製）を 用いて測定した，被験者は，室温が調整された部屋（24 $\left.\sim 26^{\circ} \mathrm{C}\right)$ ，湿度50～70\%の環境下で姿勢による影響を除 くために，各条件の運動前および運動終了後に15分間の 仰臥位安静をとり, 同姿勢時の心音図, 心電図, 脈波, 四肢血圧掞よびHRの測定を実施した。測定は，すべて 同一験者が実施しており，測定時刻は被験者ごとに随時 異なったが，両条件の一過性運動は，ほぼ同一時刻に測 定した。また，測定の前日より激しい運動，動脈機能に 影響を及ぼすアルコール，カフェインおよび塩分濃度の 高い食事摂取などを制限した。

被験者の両上腕㧍よび両足首に血圧測定用カフを巻 き，カフ内の容積脈波から両上腕および両足首の脈波か ら立ち上がり時間の差を（ $\Delta \mathrm{T} ）$ を測定し，身長から求 めた大動脈弁口から足首までの長さ $(\mathrm{La})$ ，大動脈弁口 から上腕の長さ $(\mathrm{Lb})$ を求め, 以下に示すような式から baPWVを算出した ${ }^{15,16)}$ ，算出式は以下に示すとおりで ある。

$$
\mathrm{baPWV}=(\mathrm{La}-\mathrm{Lb}) / \Delta \mathrm{T}
$$

また，再現性を検討するために17名の被験者を対象 に同一時間帯に日を変えてbaPWVを 3 回測定して級内 相関係数 (intraclass correlation coefficient: ICC) を算 出したところ， baPWVはそれぞれ $1165.9 \pm 106.7 \mathrm{~cm}$ ・ $\mathrm{sec}^{-1}, 1152.2 \pm 100.7 \mathrm{~cm} \cdot \mathrm{sec}^{-1}, 1164.4 \pm 103.9 \mathrm{~cm} \cdot \mathrm{sec}^{-1}$, ICC=0.98であった.

統計処理 本研究の全ての結果は，平均值および標準偏 差で示した。一過性運動の効果を検討するために, SBP, DBP，baPWV およびHR と一過性運動中の $\dot{\mathrm{V}} \mathrm{O}_{2}$ および $\mathrm{HR}$ の両条件間の比較には対応のある $\mathrm{t}$ 検定，各測定項 目の運動前後の経時変化は反復測定による二元配置分散 分析を行い，事後検定にはBonfferoni法をそれぞれ用い た。また，統計解析には，危険率は全て $5 \%$ 未満を有意 水準として採用した 
結果

一過性運動時のV் $\mathrm{O}_{2}$ およびHRの変化 IE 条件および $\mathrm{CME}$ 条件の一過性運動中の $\dot{\mathrm{V}} \mathrm{O}_{2}$ およびHRの変化につ いては，Fig. 1に示す通りである。 IE 条件の高強度運動 中では, $\dot{\mathrm{V}} \mathrm{O}_{2}$ および $\mathrm{HR}$ が $\mathrm{CME}$ 条件と比較して高值であ り，両条件間に有意な差が認められた $(p<0.01)$.

各条件の一過性運動前後のSBP, DBP, baPWV および HRの変化 (Table 1) IE 条件およびCME条件の一過
性運動前後のSBP, DBP, baPWV およびHRの変化に ついては, Table 1 に示す通りである。一過性運動前と 比較して運動終了15分後のbaPWVは, IE 条件では低下 しており，運動前後で有意な差が認められた（ $<<0.01 ）$. CME 条件では, 有意な差は認められなかった。両条件 の上腕および足首のSBPおよびDBPについては, 運動 前後で有意な差は認められなかったが，HRについては, 両条件ともに運動前と比較して運動後で高值であり, 有 意な差が認められた $(\mathrm{p}<0.01)$. また, 運動後のbaPWVは, IE条件で低下しており，CME条件と比較して有意な差
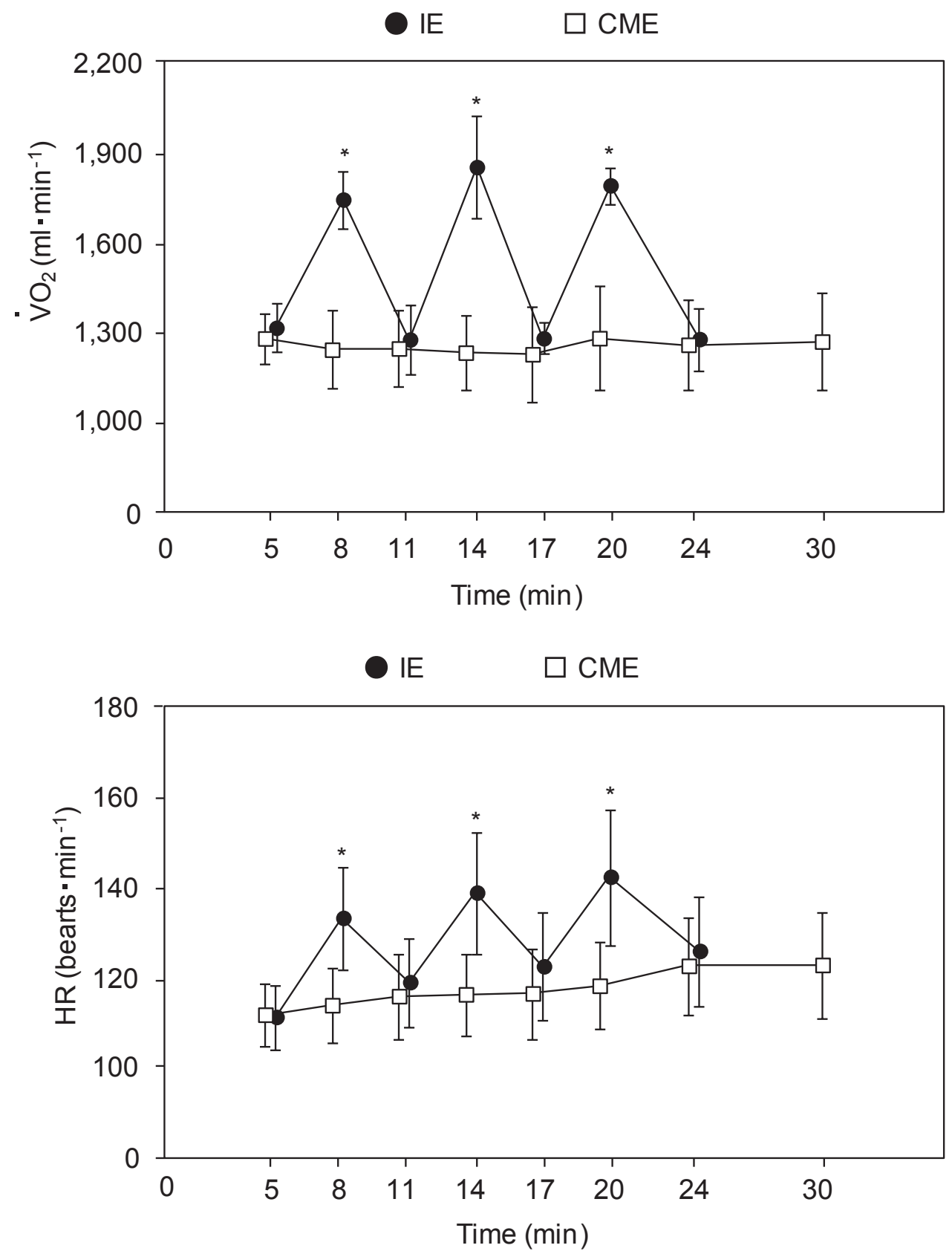

Fig. 1 Changes in $\dot{\mathrm{VO}}_{2}$ and $\mathrm{HR}$ during acute exercise Values are means $\pm \mathrm{SD}$.

IE: interval exercise, CME: continuous moderate exercise.

$*$ : Significant $(p<0.01)$ difference between IE and CME. 
が認められた（ $\mathrm{p}<0.01 ）$ 。また，運動後の HRは，IE条 件で上昇して抢り，CME条件と比較して有意な差が認 められた $(\mathrm{p}<0.01)$.

\section{考察}

本研究では, 正常血圧の成人男性を対象に自転車エル ゴメータを用いて，短時間の高強度および中強度運動 から構成されるインターバル形式の一過性運動による baPWVの変化を中強度の持続的運動と比較検討した。 その結果, IE 条件では, 運動前と比較して運動終了15 分後のbaPWVが低下しており, 運動前後では有意な差 が認められた。 baPWVが低下した原因の一つとして は, 運動時の血流量の増加にともなう血管壁へのshear stressが持続的に増加することで，血管内皮細胞由来の 血流依存性血管拡張物質である $\mathrm{NO}$ の増加の影響が考え られる，本研究でのbaPWVの低下は，一過性運動前後 の結果であるために，1時間後には運動開始前の水準に 戻ると推測される ${ }^{17)}$ が, Ciolac $^{7)}$ らは, インターバル形式 の一過性運動を実施することで, 安静時と比較してNO の増加抢よび血管収縮物質であるエンドセリン -1 濃度 が減少したと報告している.したがって, 短時間インター バル形式の一過性運動を継続的に実施することで，持続 的運動よりも効果的に動脈スティフネスを改善させる可 能性が示唆される。
運動終了15分後のHRについては，IE条件と CME 条 件との間に有意な差が認められた。また， IE 条件の高 強度運動終了時の HRは, $\mathrm{CME}$ 条件と比較して有意に 上昇していることから，運動中および終了後の心拍出 量が増加していたことが推測される。また，Tordi ${ }^{8}$ ら は，30分間のインターバル形式の一過性運動終了から 30分後の心拍出量が持続的運動と比較して増加してお り，頸動脈－足首間のPWVに改善が認められたと報告 している，したがって，IE条件では心拍出量の増加によ り shear stress が運動中から終了後も持続的に増大寸る ことでNOがより一層放出され，一過性の動脈の機能的 な変化を生じさせた可能性が考えられる，さらに，血管 平滑筋弛緩作用を有する心房性ナトリウム利尿ペプチ ド（ANP）は，心房筋の伸展により生合成分泌が生じ るために, 静脈還流量の増加が予測されるIE条件では, ANPがより一層増加してbaPWVが低下した可能性も 考えられる18).

一方， $\mathrm{CME}$ 条件では，IE条件とは異なり一過性運動 前後の baPWVに有意な差が認められなかった。これま で，65\% $\mathrm{V}_{2 \max }$ の30分間の持続的な自転車こぎ運動を することで, 運動前と比較して運動終了後のleg PWVは 有意に低下することが報告されている ${ }^{19)}$. 本研究では, 運動強度を高血圧治療ガイドラインにより推奨されてい る50\% $\mathrm{V}_{2 \max }$ に設定しており, 先行研究20) と比較して運

Table 1. Changes in SBP, DBP, baPWV and HR between pre and post acute exercise

\begin{tabular}{|c|c|c|c|c|}
\hline & \multicolumn{2}{|c|}{ IE } & \multicolumn{2}{|c|}{ CME } \\
\hline & pre & post & pre & post \\
\hline \multicolumn{5}{|c|}{ Brachial blood pressure } \\
\hline $\mathrm{SBP}(\mathrm{mmHg})$ & $115.8 \pm 6.6$ & $115.6 \pm 7.6$ & $117.2 \pm 7.1$ & $118.0 \pm 7.7$ \\
\hline $\mathrm{DBP}(\mathrm{mmHg})$ & $67.4 \pm 5.6$ & $66.3 \pm 5.7$ & $67.8 \pm 8.1$ & $68.8 \pm 5.1$ \\
\hline \multicolumn{5}{|l|}{ Ankle blood pressure } \\
\hline $\mathrm{SBP}(\mathrm{mmHg})$ & $131.8 \pm 6.9$ & $126.1 \pm 12.0$ & $131.9 \pm 10.3$ & $131.9 \pm 10.7$ \\
\hline $\mathrm{DBP}(\mathrm{mmHg})$ & $70.1 \pm 6.6$ & $65.9 \pm 7.9$ & $70.3 \pm 7.8$ & $69.7 \pm 6.3$ \\
\hline baPWV $\left(\mathrm{cm} \cdot \mathrm{sec}^{-1}\right)$ & $1181.9 \pm 119.2$ & $1108.4 \pm 109.4^{*} \dagger$ & $1173.5 \pm 137.1$ & $1164.8 \pm 96.0$ \\
\hline $\mathrm{HR}$ (beats $\left.\cdot \mathrm{min}^{-1}\right)$ & $60.8 \pm 5.4$ & $79.2 \pm 7.3^{*} \dagger$ & $59.6 \pm 7.0$ & $65.2 \pm 7.2^{*}$ \\
\hline
\end{tabular}

Values are means $\pm \mathrm{SD}$.

IE: interval exercise, CME: continuous moderate exercise.

SBP: systolic blood pressure, DBP: diastolic blood pressure, baPWV: brachial - ankle pulse wave velocity, HR: heart rate.

$*$ Significant $(\mathrm{p}<0.01)$ difference between pre- and post-exercise.

$\uparrow$ : Significant $(\mathrm{p}<0.01)$ difference between IE and CME. 
動強度が低く，運動時間が同じであるために仕事量が小 さいことがbaPWVの結果に影響したと考えられる.

Nakaら ${ }^{19)}$ は, 約15分の最大運動負荷テス卜後に運動 前と比較してbaPWVに有意な低下が認められたと報告 している. しかし, この研究では, 運動終了 3 分後の SBPが $180 \mathrm{mmHg}$ を超えているために, 循環器疾患予防 の定期的なインターバルトレーニングとして, 高強度の 最大下運動を実施することは, 安全面から問題がある. したがって，心負荷のリスクを軽減するために，短時間 で動脈機能の改善に効果がある運動条件を検討する必要 がある. 本研究のIE 条件は先行研究 ${ }^{5-7)}$ と比較して運動 時間を約15分短縮したにもかかわらず，一過性運動後の baPWVに低下がみられた。したがって, 高強度と中強 度でインターバル形式の運動を構成することで短い運動 時間でbaPWVの低下をもたらす可能性がある.

なお，本研究の限界として，運動終了15分以降の動脈 機能を測定していない点, 心拍出量, 自律神経活動, 血 中 NO濃度および血中 ANP濃度などを測定していない 点, トレーニングによる影響を検討していない点, 対象 者が若年者であり, 中高齢者を対象にしていない点があ げられる，今後，これらの点を考慮して，動脈機能の改 善を目的としたインターバルトレーニングを確立するた めの検討が必要である.

\section{結 論}

本研究は, 20歳代の正常血圧の男性を対象に短時間の 高強度㧍よび中強度運動から構成されるインターバル形 式の一過性運動がbaPWVに及ぼす影響を検討した。 そ の結果, 持続的運動とは異なり, インターバル形式の一 過性運動は, 運動前と比較して運動終了後にbaPWVが 低下した。したがって, 高血圧治療ガイドラインで推 奨されている持続的運動より, 短時間の高強度および 中強度運動から構成されるインターバル形式の運動は, baPWVを低下させる可能性が示された。

\section{文献}

1）厚生統計協会. 国民衛生の動向 - 厚生の指標, 増刊, 奥村 印刷, 東京, 48-49, 2010.

2) Tomiyama H, Yamashina A, Arai T, Hirose K, Koji Y, Chikamori T, Hori S, Yamamoto Y, Doba N, Hinohara S. Influences of Age and Gender on Results of Noninvasive Brachial-Ankle Pulse Wave Velocity Measurement a Survey of 12517 Subjects. Atherosclerosis 166: 303-309, 2003.

3) Yamashina A, Tomiyama H, Arai T, Hirose K, Koji Y, Hirayama Y, Yamamoto Y, Hori S. Brachial-ankle pulse wave velocity as a marker of atherosclerotic vascular damage and cardiovascular risk. Hypertension Res 26: 615-622, 2003.
4) Tanaka H, Dinenno FA, Monahan KD, Clevenger CM, DeSouza CA, Seals DR. Aging, Habitual Exercise, and Dynamic Arterial Compliance. Circulation 102: 12701275, 2000.

5) Tjønna AE, Lee SJ, Rognmo $\varnothing$, Stølen TO, Bye A, Haram PM, Loennechen JP, Al-Share QY, Skogvoll E, Slørdahl SA, Kemi OJ, Najjar SM, Wisløff U. Aerobic Interval Training Versus Continuous Moderate Exercise as a Treatment for the Metabolic Syndrome: A Pilot Study. Circulation 118: 346-354, 2008.

6) Wisløff U, Støylen A, Loennechen JP, Bruvold M, Rognmo Ø, Haram PM, Tjønna AE, Helgerud J, Slørdahl SA, Lee SJ, Videm V, Bye A, Smith GL, Najjar SM, Ellingsen $\varnothing$, Skjaerpe T. Superior cardiovascular effect of aerobic interval training versus moderate continuous training in heart failure patients a randomized study. Circulation 115: 3086-3094, 2007.

7) Ciolac EG, Bocchi EA, Bortolotto LA, Carvalho VO, Greve JM, Guimaraes GV. Effects of high-intensity aerobic interval training vs. moderate exercise on hemodynamic, metabolic and neuro-humoral abnormalities of young normotensive women at high familial risk for hypertension. Hypertens Res 33: 836-843, 2010.

8) Tordi N, Mourot L, Colin E, Regnard J. Intermittent versus constant aerobic exercise: effects on arterial stiffness. Eur J Appl Physiol 108: 801-809, 2010.

9) Haskell WL, Lee IM, Pate RR, Powell KE, Blair SN, Franklin BA, Macera CA, Heath GW, Thompson PD, Bauman A. Physical activity and public health: updated recommendation for adults from the American College of Sports Medicine and the American Heart Association. Circulation 116: 1081-1093, 2007.

10) Singh JP, Larson MG, Manolio TA, O'Donnell CJ, Lauer M, Evans JC, Levy D. Blood pressure response during treadmill testing as a risk factor for new-onset hypertension. The Framingham heart study. Circulation 13: 1831-1836, 1999.

11）日本高血圧学会高血圧治療ガイドライン作成委員会. 高血圧治療ガイドライン, ライフサイエンス出版, 東京, 34-35, 2001.

12）山地啓司. 最大酸素摄取量の科学, 杏林書院, 東京, $3-55$, 2001.

13) Gaiga MC, Docherty D. The Effect of an Aerobic Interval Training Program on Intermittent Anaerobic Performance. Can J Appl Physiol 20: 452-464, 1995.

14) Lesmes GR, Fox EL, Stevens C, Otto R. Metabolic response of females to high intensity interval training of different frequencies. Med Sci Sports 10: 229-232, 1978.

15）山科 章, 小澤利男, 増田善明編. 脈波速度測定法, 脈波速 度,メジカルビュー社, 東京, 26-34, 2002.

16）富山博史, 山科 章, 西沢良記. 動脈壁硬化の診断·測定法, Arterial Stiffness の臨床, メディカルレビュー社, 大阪 · 東京, 19-24, 2005.

17) Sugawara J, Otsuki $T$, Tanabe $T$, Maeda S, Kuno S, Ajisaka R, Matsuda M. The effects of low-intensity single-leg exercise on regional arterial stiffness. Jpn $J$ Physiol 53: 239-241, 2003. 
18) Kingwell BA, Berry KL, Cameron JD, Jennings GL, Dart AM. Arterial compliance increases after moderate-intensity cycling. Am J Physiol 273: 2186-2191, 1997.

19) Naka KK, Tweddel AC, Parthimos D, Henderson A, Goodfellow J, Frenneaux MP. Arterial distensibility: acute changes following dynamic exercise in normal subjects. Am J Physiol Heart Circ Physiol 284: 970-978, 2003.

20) Onuoha GN, Nicholls DP, Patterson A, Beringer T. Neuropeptide secretion in exercise. Neuropeptides 32: 319-325, 1998. 